Acta Hispanica (2017) 22: 45-53

\title{
LA PRESENCIA DE LOS NAHUATLISMOS EN EL ESPAÑOL DE MÉXICO DESDE UN ENFOQUE DIACRÓNICO
}

\author{
INGRID PETKOVA \\ Universidad de Pedagogía de Cracovia \\ "Nada, en nuestro sentir, simboliza tan cumplidamente a la patria como la lengua" \\ (Rufino José Cuervo) ${ }^{1}$
}

\begin{abstract}
Resumen: El presente artículo tiene como objetivo presentar brevemente la historia de los contactos lingüísticos entre el español hablado en México y las lenguas autóctonas de este país, más concretamente, el náhuatl. Por otra parte se hablará sobre el fenómeno lingüístico del nahuatlismo y su presencia en la literatura mexicana desde un punto de vista diacrónico.
\end{abstract}

Palabras clave: contactos lingüísticos, náhuatl, México, influencia léxica, lingua franca

\begin{abstract}
The aim of this article is, on one hand, to talk about the language contacts between Mexican Spanish and the indigenous languages of Mexico, more specifically Nahuatl; on the other hand, to introduce the linguistic phenomenon of Nahuatl loanwords and their presence in the Mexican literature from diachronic point of view.
\end{abstract}

Keywords: linguistic contacts, Nahuatl, Mexico, loan words, lingua franca

\section{Introducción}

Como es sabido, la influencia de las lenguas indígenas da un rasgo característico al español hablado en América. Esto es válido también para el español hablado en México que les debe a las lenguas autóctonas numerosas palabras usadas aún hoy en día. Entre estas lenguas destacan el náhuatl y el maya que tienen el mayor número de hablantes en este país y que también tienen el mayor impacto cultural.

Esta influencia se reduce casi exclusivamente al ámbito del vocabulario en los territorios monolingües españoles. Entre los pocos fenómenos gramaticales que se pueden atribuir al náhuatl en el español hablado en México podemos mencionar el uso, cada vez menos frecuente del sufijo -eco $(<-$ ecatl) en la formación de algunos gentilicios como guatemalteco o chiapaneco. ${ }^{2}$

\footnotetext{
${ }^{1}$ Guillermo L. GUITARTE - Rafael TORRES QUINTERO, "Linguistic correctness and the role of the Academies in Latin-America" in: Joshua A. FISHMAN (ed.), Advances in Language Planning, The Hague, Mouton, 322.

2 Juan M. LOPE BLANCH, "La influencia del sustrato en la gramática del español mexicano", in: Juan M. LOPE BLANCH, Estudios sobre el español de México, México, UNAM, 1972, 164.
} 
La presencia de los nahuatlismos en el español de México desde un enfoque diacrónico

Desde el punto de vista fonético se puede mencionar "la pronunciación de la $t$ como licuamente de l (tlapalería, a-tlas, nábuatl) sin dificultad ninguna”. Según Lope Blanch esto se debe a que en las lenguas indígenas y más concretamente en el náhuatl existe un sonido alveolodental lateral sordo parecido a $-t l-$. El lingüista también menciona como rasgos peculiares los fonemas $\hat{s}$ y $\breve{s}$ en palabras de origen prehispánico, sobre todo en topónimos como Xochicalco o Tzintzuntran. ${ }^{3}$

Sin embargo, en el vocabulario es donde se puede observar, en mayor medida, la influencia de las lenguas indígenas y más concretamente del náhuatl.

Varios vocablos pertenecen a los así llamados "mexicanismos históricos" que se han incorporado a la lengua desde el siglo XVI, palabras como tomate, hule, chocolate, petaca, etc. ${ }^{4}$ Algunos de estos se usan en otras variantes hispanas o incluso en otras lenguas.

Sin embargo, la mayoría pertenece exclusivamente al habla mexicana y le da una personalidad léxica propia. En muchos casos los nahuatlismos coexisten con las palabras españolas generales, como guajolote y pavo; cuate y amigo; chamaco y niño. Otras veces la voz nahua tiene un matiz especial, por ejemplo tianguis es 'el mercado indígena' o tlapalería 'un tipo especial de ferretería'. En otros casos el vocablo nahua ha sustituido la correspondiente hispana: tecolote por búho o chapulín por saltamontes. ${ }^{5}$

Pero antes de entrar en más detalles sobre el vocabulario, veamos de qué naturaleza eran las relaciones entre los colonizadores españoles y la población autóctona y cómo este hecho se reflejó en el uso de la lengua de cada uno.

\section{Los contactos lingüísticos entre el español y el náhuatl}

El encuentro entre lo indígena y lo español fue un proceso muy complicado debido a las diferencias culturales y a las diferentes visiones del mundo. El primer objetivo aparente de la conquista (el verdadero fue de naturaleza económica y política naturalmente) fue la conversión de los indios al cristianismo. En esta actividad, la diversidad de la lenguas constituyó un obstáculo enorme, por ello los misioneros vieron que era necesario emplear una lingua franca que en México fue el náhuatl, que poco después ganó más territorio, incluso más que durante el imperio azteca. De hecho, los mismos monjes decían que a los indígenas se les dificultaba mucho la adquisición de la lengua española. Adicionalmente, el número de misioneros era muy bajo en comparación con la cantidad de indios; debido a esto, a los religiosos les parecía una tarea excesiva e innecesaria enseñar el español a los aborígenes. Los indios catequizados vivían en sus propias aldeas, hacían trabajos de agricultura y de artesanía y gozaban de cierta protección, así que para ellos -según los misioneros- el hecho de no saber el castellano

\footnotetext{
${ }^{3}$ Juan M. LOPE BLANCH, "Estado actual del español en México", in: LOPE BLANCH, op. cit., 25.

${ }^{4}$ Ibidem, 26.

${ }^{5}$ Idem.
} 
significaba una defensa contra los peligros que les esperaban fuera de este mundo. De este modo, una barrera invisible separaba el mundo de los españoles y de los indígenas. ${ }^{6}$

Después la situación cambió paulatinamente. En la segunda mitad del siglo XVI Carlos V emitió dos Cédulas Reales para fomentar la castellanización, aunque en varias ocasiones el Rey tuvo una actitud ambivalente respecto al tema y dejó en manos de los religiosos la enseñanza del castellano. Esta época se caracteriza por una dicotomía: la Iglesia, cuyo principal objetivo era la catequización, prefería usar con este fin las lenguas autóctonas; mientras que el poder civil, que tenía fines más prácticos, se inclinaba hacia el español. ${ }^{7}$

En el siglo XVIII se formó una nueva manera de pensar en la que el cultivo de la lengua española tenía un papel primordial. En 1767 casi tres mil jesuitas fueron expulsados de América y este hecho repercutió decisivamente en el destino de las lenguas indígenas, ya que los jesuitas eran los que principalmente usaban las lenguas de los aborígenes en la catequización y en la enseñanza. ${ }^{8}$

Otro hecho histórico importante que debemos mencionar aquí es la Cédula Real de Carlos III del año 1770 que ordena que “ [...] de una vez se llegue a conseguir el que se extingan los diferentes idiomas de que se usa en los mismos dominios [americanos] y solo se hable el castellano". ${ }^{9}$

Al lograr la independencia las sociedades hispanoamericanas contaban con una enorme población indígena que no hablaba el español y una minoría de criollos blancos, que tenía todo el poder y naturalmente hablaba solo el castellano. En esta época cuando el objetivo principal fue la formación de un nuevo estado con su propia economía y cultura- se veía a los indígenas como un obstáculo que dificultaba la realización de estos objetivos y las poblaciones indígenas quedaron marginadas en la sociedad mexicana " $[. .$.$] para dignificar al indio no se pretendía fomentar el cultivo del$ nahua, del otomí o del maya: el lema era "castellanizar y calzar al indio."10

Entonces empezaron grandes campañas de castellanización que en muchos casos fracasaron, debido a la gran variedad de lenguas autóctonas. Por ejemplo, en el México actual se estima que existen 53 grupos étnicos (constituidos por cinco millones de personas) que hablan 105 lenguas indoamericanas pertenecientes a distintas familias, que sin embargo, con excepción del náhuatl y del maya y unas pocas lenguas más, son lenguas en retroceso continuo. ${ }^{11}$

${ }^{6}$ José G. MORENO DE ALBA, El español de América, México, Fondo de Cultura Económica, 2000, 49-50.

${ }^{7}$ Humberto, LÓPEZ MORALES, La aventura del español en América, Madrid, Espasa, 1998, 61-64.

${ }^{8}$ MORENO DE ALBA, op. cit., 55.

${ }^{9}$ LÓPEZ MORALES, op. cit., 67.

${ }^{10}$ Rafael LAPESA MELGAR, "Nuestra lengua en España y en América”, in: Revista de Filología Española, 72, 1992, 269.

${ }^{11}$ LÓPEZ MORALES, op. cit., 73. 
La presencia de los nahuatlismos en el español de México desde un enfoque diacrónico

Desgraciadamente, la expansión del español ha tenido como consecuencia el abandono masivo de las lenguas indígenas que en muchos casos ha llevado a su extinción. López Morales explica este fenómeno desde un punto de vista económico y menciona como ejemplo a México: “¿Cómo podría el Gobierno mexicano, de cuya vocación indigenista no debería dudarse, atender a las casi quince lenguas, con muchos y diversos dialectos cada una de ellas, que se hablan en un solo Estado, el de Oaxaca, cuando algunas de ellas no cuenten con más de doscientos hablantes? En estos casos, la única respuesta posible, al menos desde el punto de vista presupuestario, es la castellanización."12

Durante el gobierno de Lázaro Cárdenas, se pudo observar cierto cambio en la ideología de la incorporación forzada de los indígenas a la cultura nacional, pero realmente sólo en la década de 1980 empezaron las transformaciones verdaderas tanto en la enseñanza (establecimiento de universidades interculturales, desarrollo de la educación primaria bilingüe, etc.) como en el discurso político: partiendo del "problema indio se pasó hacia la ideología de multiculturalismo y los derechos de los indígenas". ${ }^{13}$

Como podemos ver, la actitud hacia las lenguas autóctonas ha cambiado notablemente a lo largo de la historia. Desde la convivencia más o menos pacífica, a través del rechazo completo y la castellanización forzada, hasta la actitud tolerante que hoy en día está formándose. A pesar del apoyo económico, político, educativo que los gobiernos últimamente dan a las lenguas autóctonas, se trata de un proceso en el que el futuro de estos idiomas, sobre todo de los que tienen escaso número de hablantes, es bastante inseguro. En general después de una o dos generaciones bilingües la siguiente ya no aprende la lengua de sus antepasados y de este modo se pierde el legado cultural y lingüístico que -en el mejor de los casos- sobrevive en la cultura mestiza del país y en la influencia lingüística, de la que hablaré en el siguiente capítulo.

\section{La aparición de los nahuatlismos (indigenismos) en el español en México}

Entre las lenguas indígenas en México indudablemente destacan dos por el número de sus hablantes y por su impacto lingüístico-cultural: el náhuatl y el maya. El náhuatl es la lengua indígena con el mayor número de hablantes en México, se estima que lo hablan un millón y medio de personas que en su mayoría son bilingües (españolnáhuatl). El náhuatl pertenece a la familia uto-azteca y desde el punto de vista tipológico es una lengua polisintética y aglutinante. El náhuatl comprende un continuum de variedades lingüísticas, algunas resultan incomprensibles entre sí, otras llevan diferentes nombres locales pero pertenecen a la misma lengua.

En 1519, la llegada de los españoles ejerció una influencia grande sobre el destino de la lengua náhuatl. Por una parte, empezó su documentación en la escritura latina lo que

\footnotetext{
${ }^{12}$ LÓPEZ MORALES, op. cit., 76.

${ }^{13}$ Magnus PHARAO HANSEN, “ The diference language makes: The Life-History of Nahuatl in Two Mexican Families”, in: Linguistic Anthropology, 1992/1, 85.
} 
contribuyó en gran medida a su preservación, y por otra, comenzó su sustitución con la lengua española, aunque este proceso -como lo hemos visto- en los primeros siglos no fue muy rápido.

Los españoles se dieron cuenta de que era una tarea imposible aprender las numerosas lenguas indígenas con las que se encontraron en el Nuevo Mundo y prefirieron usar el náhuatl como lingua franca cuando se comunicaban con los aborígenes. Al mismo tiempo los misioneros también vieron que era más fácil difundir la fe católica entre los indígenas en su propia lengua o por lo menos en una lengua que no les pareciera muy distante. Con este objetivo empezaron a escribir gramáticas de náhuatl, artes como ellos las llamaban. La primera que se conservó hasta nuestros días es de Andrés de Olmos que data de 1547.

Cuando los conquistadores llegaron al Nuevo Mundo para denominar las nuevas realidades recurrían a varios métodos: crearon expresiones basadas en palabras españolas camisa de la tierra por huipil, o las emplearon con otro valor semántico (tortilla en México es un 'pan muy delgado de forma redonda, de maíz y cocido en comal') o tomaron prestados vocablos de las lenguas indígenas. ${ }^{14}$

Con la llegada de Hernán Cortés a México en 1519 entraron en la lengua española los primeros nahuatlismos, sobre todo topónimos y nombres de personas pero también nombres de plantas y animales y otras realidades que eran características del continente americano y no se conocían en Europa.

Entre los escritos de Hernán Cortés destacan las cinco Relaciones que envió a Carlos I entre 1519 y 1526, en los que narra la conquista del imperio mexicano. Estos documentos son muy interesantes porque a través de ellos podemos observar los primeros contactos lingüísticos entre el castellano y las lenguas indígenas. Estos textos contienen los primeros antillanismos aplicados a las cosas típicas de la Nueva España y los primeros nahuatlismos. ${ }^{15}$

Veamos algunos ejemplos de los últimos:

- acal 'embarcación de remo' (“y vieron cómo todos los naturales della la desamparaban, y unos con sus haciendas se iban a meter en la laguna con sus canoas, que ellos llaman acales” M575a). Proviene de atl 'agua' y calli 'casa'. Es sustituida por el antillanismo canoa. ${ }^{16}$

- cacao ("porque, como es tiempo agora de coger el cacao, estorban los de Culúa con las guerras" M69b) Según unos (Molina, Cabrera) es de origen náhuatl; según otros (Barrera) es un préstamo maya adoptado por los nahuas. ${ }^{17}$

\footnotetext{
${ }^{14}$ Huguette POTTIER NAVARRO, "El concepto del americanismo léxico", in: Revista de Filología Española, 1992/72, 298.

15 José ENGUITA UTRILLA, "Voces amerindias en las "Relaciones" de Hernán Cortés", in: Revista de Filología Española 1992/72, 379-381.

${ }^{16}$ Ibidem, 382.

${ }^{17}$ Ibidem, 384.
} 
La presencia de los nahuatlismos en el español de México desde un enfoque diacrónico

- ochilobus 'dios de la guerra' (“que por qué yo así brevemente los acababa de matar y los quitaba de penar tanto, porque ellos tenían deseos de morir y irse al cielo para su Ochilobus que los estaba esperando para descansar; y este ídolo es el que en más veneración tienen" M87b). Según Robelo viene de huitrilin 'colibri' y opochtli 'izquierdo, sangriento'. También aparece en la Historia de Fernández de Oviedo, a veces con el significado 'templo, casa de oración'. 18

- panicap 'bebida indígena' ("E trajéronme diez platos de oro y mil y quinientas piezas de ropa, y mucha provisión de gallinas y panicap, ques cierto brebaje que ellos beben" M21b). ${ }^{19}$

- tianguizco 'mercado' ("había tres calles dende lo que teníamos ganado, que iban a dar al mercado, al cual los indios llamaban Tianguizco" M79b). La acepción original ya es anticuada pero el vocablo tianguis todavía se utiliza como 'feria, compra y venta de mercaderías'. ${ }^{20}$ Lope Blanch agrega el significado de 'plaza' en el DF. ${ }^{21}$

En total podemos encontrar 21 indoamericanismos, la mayor parte del taíno, el resto del náhuatl. Es un número bajo comparando con los 200 recopilados por Lope Blanch del siglo XVI y los primeros años del siglo XVII o los 76 que usa Fernández de Oviedo en su Generaly natural historia de las Indias. ${ }^{22}$

Enguita Utrilla resalta la actitud diferente que adopta Hernán Cortés ante las palabras autóctonas según su procedencia. Los nahuatlismos siempre van acompañados con notas explicativas para facilitar su comprensión para los que desconocen el mundo colonial, mientras que los términos antillanos se tratan como patrimoniales del español y pocas veces se explican. ${ }^{23}$

Este hecho está relacionado con el fenómeno que Clemente Zamora menciona: él dice que 63 de 69 préstamos léxicos taínos se usaban fuera de las Antillas, mientras que de 95 vocablos nahuas sólo 39 se oían fuera de su territorio. Tal diferencia se explica porque "one reason, only recently discussed, is the special type of prestige of experience $[\ldots]$. Loanwords were not only signs, but also symbols." 24 Es decir, los conquistadores al utilizar palabras antillanas demostraban su experiencia y demostraban su participación en las primeras conquistas, lo que les daba prestigio, otra prueba de la estrecha relación entre la lengua y las circunstancias históricas y sociales.

\footnotetext{
${ }^{18}$ Ibidem, 388.

${ }^{19} \mathrm{Idem}$.

${ }^{20}$ Idem.

${ }^{21}$ Juan M. LOPE BLANCH, Léxico indigena en el español de México, México, El Colegio de México, 1979, 80.

22 Ibidem, 391.

${ }^{23}$ Ibidem, 392.

${ }^{24}$ Juan CLEMENTE ZAMORA, "Amerindian loanwords in general and local varieties of American Spanish”, in: Word, 1982/33, 165-167.
} 
Otra obra importante desde el punto de vista del uso de los indigenismos es el Sumario de la natural historia de las Indias de Gonzalo Fernández de Oviedo escrita en 1525. Contiene 70 palabras de origen indígena y sólo los usa cuando es imprescindible para la descripción. Se puede suponer que en el habla cotidiana se usaban muchas más. ${ }^{25}$

Su otra obra, General y natural historia de las Indias ya incluye tantos indigenismos que a Oviedo le parece necesario disculparse: "si algunos vocablos extraños e bárbaros aquí se hallasen la causa es la novedad de que tractan, y no se pongan a la cuenta de mi romance $[. .$.$] y lo que aviene en este volumen [...] serán nombres o palabras puestos$ para dar a entender las cosas que por ellas quieren los indios significar". A mediados del siglo XVI Oviedo escribe la segunda parte de su historia en el que se pueden encontrar más de 500 indigenismos. ${ }^{26}$

Este cronista tiene una actitud parecida a sus contemporáneos hacia el léxico del Nuevo Mundo: intenta emplear palabras castellanas para las realidades americanas. Así llama lagarto al 'caimán', pavo al 'guajolote' o pimiento al 'ají'. Pero no siempre encuentra el término adecuado, a veces cae en confusiones conceptuales, por ejemplo, llama peras a los aguacates. ${ }^{27}$

Además de las crónicas e historias americanas, en los siglos XVI y XVII también aparecen muchos indigenismos en la literatura peninsular. Cervantes usa entre otros: cacao, caimán, huracán, caribe, etc. Lope de Vega intencionadamente usa muchos, cerca de 80 , entre estos, varios aparecen en comedias de tema americano. ${ }^{28}$

Después de Nebrija muchos autores de diccionarios introdujeron varios indigenismos como Cristóbal de las Casas (1570), César Oudin (1607) o Covarrubias (1611); por ejemplo, cacao, piragua, guanaco, mahiz: ${ }^{29}$

Mientras tanto en el continente americano se estaban formando las variedades locales del español, aunque este hecho se notaba poco en la literatura local, ya que esta siempre intentaba imitar la de la Península. Sólo en la época de la Independencia empezaron a aparecer textos literarios con palabras indígenas o alusiones a la cultura indígena. Las primeras obras lexicográficas locales tuvieron el propósito de juzgar y corregir los "barbarismos". Más tarde, la aparición del realismo, del naturalismo y del modernismo en la literatura favoreció el uso de los indigenismos. Por esta razón sería que "cuando entra el siglo XX, las literaturas regionales compiten entre sí por llevar al plano de la lengua universal los nombres típicos de la fauna, la flora, los instrumentos, las instituciones" 30 .

\footnotetext{
${ }^{25}$ MORENO DE ALBA, op. cit., 59.

${ }^{26}$ Idem.

${ }^{27}$ Ibidem, 60 .

${ }^{28}$ LÓPEZ MORALES, op. cit., 68.

${ }^{29}$ ENGUITA UTRILLA, op. cit., 392.

${ }^{30}$ MORENO DE ALBA, op. cit., 55.
} 
La presencia de los nahuatlismos en el español de México desde un enfoque diacrónico

A modo de resumen, con las palabras de Moreno de Alba se puede decir que “[...] las lenguas indias fueron y son una fuente importante de léxico; que los indigenismos se mezclaron con el español general en el español hablado en América; que se dan en la literatura como parte del proceso de formación de las literaturas nacionales; y que los diccionarios no pueden en general ser considerados como un reflejo fiel del estado actual del proceso de la colonización lingüística" ${ }^{31}$.

Volviendo a la influencia de la lengua náhuatl sobre el español hablado en México, Roberto Moreno comenta que "ya las cocinas criollas del siglo XVI incluían metates y molcajetes, moles, chile y aguacates" 32 . De este modo se puede afirmar que "bien pronto el náhuatl y los nahuatlismos se convirtieron en parte sustancial de la conciencia criolla. Muchos españoles que por aquí anduvieron los usaron para insultar al criollo"33. Por ejemplo Cervantes para burlarse de una persona, dice: "Bendita sea una y mil veces (...) la chichigua que le dio de mamar (...)"34.

Según Moreno a los criollos les gustaba utilizar este tipo de vocabulario, sobre todo en el siglo XVII con el esplendor del barroco y el desarrollo de la conciencia criolla, y cita como ejemplo al capitán Alonso Ramírez de Vargas que en una de sus quintillas dedicada a San Bernardo de México en 1691 dice lo siguiente:

"Mexicanos, otomites, tarascos y macehuales, se dejaron los mezquites

allá, entre nacatamales, por quemar matlacahuites." ${ }^{35}$

El barroco se caracterizaba por la aceptación de las raíces culturales y lingüísticas propias, lo que más tarde, en la segunda mitad del siglo XVIII en el racionalismo sería rechazado y burlado, tomado por vulgar. En la época del neoclasicismo otra vez se levantó el interés por el pasado prehispánico "concebido como clásico propio". Las razones eran ideológicas pues "en esta labor se finca buena parte de la ideología de la independencia. Para que el nuevo país naciera había de mudarle el nombre: ya no más la España Nueva; Imperio Mexicano, Imperio de Anáhuac o México [...]"36. Sin embargo esto no implica una reivindicación de la lengua náhuatl como lengua nacional, pues "quizá por la aspiración de convertirse en un país como cualquier otro del mundo, el náhuatl y los nahuatlismos se soterraron. Quedaron como ejemplo de habla popular y solamente salieron a luz cuando la conciencia nacional se veía en peligro" 37 .

\footnotetext{
${ }^{31}$ Idem.

32 Roberto MORENO, Los nahuatlismos en el español de México, México, UNAM, 1995, 17-18.

${ }^{33}$ Ibidem, 18.

${ }^{34}$ Ibidem, 19.

35 Ibidem, 23.

${ }^{36} \mathrm{Ibidem}, 32$.

${ }^{37}$ Ibidem, 33.
} 
En resumen, el uso y el desuso de los nahuatlismos en México está estrechamente vinculado con los intereses político-nacionales. Cuando se ve la necesidad de reafirmar la identidad mexicana, se recurre muchas veces al pasado prehispánico y a las lenguas y culturas indígenas. Pero cuando la tendencia vigente en la política es "incorporarse" al grupo de los países avanzados como España o Estados Unidos, entonces el legado cultural indígena es algo para ocultar, algo de lo que se siente vergüenza. En este último caso, las palabras de origen indígena se consideran vulgares e incultas y el purismo lingüístico pasa a estar en boga. El estudio de los nahuatlismos en la lengua española no debe realizarse exclusivamente desde el punto de vista lingüístico. Es sumamente importante entender los procesos históricos, étnicos, políticos que condicionan el uso de este tipo de vocabulario. También es importante resaltar que la presencia y persistencia de los nahuatlismos en el español de México se debe al hecho de que la lengua y la cultura náhuatl siempre han formado y formarán parte de la cultura mestiza mexicana en su más amplio sentido. 